\title{
Viral Nucleic Acids in the Serum Are Dependent on Blood Sampling Site in Patients with Clinical Suspicion of Myocarditis
}

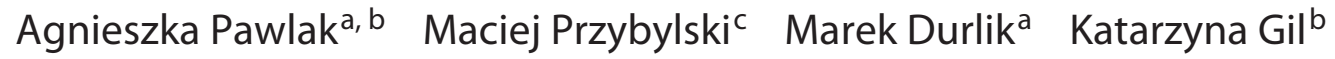 \\ Anna M. Nasierowska-Guttmejer ${ }^{d}$ Katarzyna Byczkowska ${ }^{\text {b }}$ Andrzej Ziemba $^{a}$ \\ Robert J. Gila, b \\ ${ }^{a}$ Mossakowski Medical Research Centre, Polish Academy of Sciences, ${ }^{b}$ Department of Invasive Cardiology, \\ Central Clinical Hospital of the Ministry of Interior, and ' Department of Medical Microbiology, Medical University, \\ Warsaw, and d Department of Pathology, Jan Kochanowski University, Kielce, Poland
}

\section{Key Words}

Cardiotropic viruses · Dilated cardiomyopathy .

Myocarditis · Active infection

\begin{abstract}
Background: The meaning of viral nucleic acids in the myocardium in many cases is difficult for clinical interpretation, whereas the presence of viral nucleic acids in the serum is a marker of active infection. We determined the diagnostic value of viral nucleic acids in ventricular serum and peripheral serum samples in comparison with endomyocardial biopsy (EMB) specimens in patients with clinically suspected myocarditis. Methods: The viral nucleic acid evaluation was performed in serum samples and EMB specimens by realtime PCR in 70 patients (age: $47 \pm 16$ years). The biopsy specimens were examined by histo- and immunohistochemistry to detect inflammatory response. Results: The viral nucleic acids were detected in ventricular and peripheral serum, and EMB samples of 10 (14\%), 14 (20\%), and 32 (46\%) patients, respectively. Notably, viral nucleic acids of the same virus as in the EMB sample were present more often in ventricular than in peripheral serum (60 vs. $7 \%, p=$
\end{abstract}

$0.01)$. A significant concurrence was observed between the positive and the negative results of viral nucleic acids present in EMB and ventricular serum ( $p=0.0001)$. Conclusions: The detection of the same viral nucleic acid type in the myocardium and in ventricular serum being significantly more frequent than in the peripheral serum may suggest that the site of the blood collection is important for more precise and reliable confirmation of the active viral replication in the heart.

(c) 2017 S. Karger AG, Basel

\section{Introduction}

Viral infections are considered to be one of the most common etiological agents not only of myocarditis (MCI), but also of inflammatory dilated cardiomyopathy (iDCM) [1]. The high prevalence of viral nucleic acids in the myocardium in patients with the suspicion of MCI as well as DCM has been proven in many studies [1-3]. Schenk et al. [4] reported the DNA presence of parvovirus $\mathrm{B} 19$ (PB19V) in endomyocardial biopsy (EMB) in almost $96 \%$ of the study population as well as in heart donors and

\section{KARGER}

(c) 2017 S. Karger AG, Basel

0300-5526/17/0593-0143\$39.50/0

E-Mail karger@karger.com

www.karger.com/int
Agnieszka Pawlak, MD, PhD

Mossakowski Medical Research Centre, Polish Academy of Sciences Pawińskiego Street 5

PL-02-106 Warsaw (Poland)

E-Mail a.pawlak1@wp.pl 
healthy people. Nowadays, the most common cardiotropic viruses are PB19V, human enterovirus (HEV), human herpesvirus type 6 (HHV-6), and human adenovirus (HAdV) [5].

The diagnosis of MCI is still based on histopathological and immunohistological assessment of EMB, but routine histological analysis is too insensitive to detect myocardial inflammation as well as active viral replication accurately [3]. Molecular techniques, such as PCR, allow the detection and quantification of the viral nucleic acids in the heart [5]. It is well known that small amounts of persistent viral nucleic acids even without immune response may lead to further progression of the disease by cytopathic effects, alteration of the extracellular matrix, or chronic myocardial inflammation, and may predict poor outcome $[1,6,7]$. The clear-cut ascertainment whereby the chronic prevalence of the viral genome in the myocardium (especially with low viral load) represents active infection and, as a consequence, leads to the development or progression of myocardial dysfunction is still difficult or impossible to evaluate. However, based on the literature, it seems that blood sample analysis can be helpful in clarifying this issue. The leukocyte sample analysis characterizes the highest sensitivity for detection of a chronically prevalent virus [8]. Nevertheless, the use of cell-free plasma or serum has been advocated by some as more indicative of active virus infection than whole blood or peripheral blood leucocytes, in which the virus load may be due to a cell-associated latent virus [9]. Several studies have shown the correlation between the risk of symptomatic disease development or the poor outcome in patients with viral infection and the viral load or dynamic changes of viral load in cell-free plasma or serum $[10,11]$. The source of viral nucleic acids in serum samples may be viral nucleic acids released from actively infected sites. For that reason, it seems probable that the presence of viral nucleic acids in serum, especially taken from the heart ventricle, could reveal possible active viral infection in the heart. Viral genome detection in the serum taken from the left ventricle for the diagnosis of active viral infection in patients with suspected MCI has not been assessed so far in clinical practice.

Proper diagnosis is needed to prevent the development of iDCM, an important cause of heart failure, which seems to be triggered by viral MCI in $35-50 \%$ of cases [12]. The purpose of this prospective study was to determine the diagnostic value of viral nucleic acids in the ventricular serum and peripheral serum samples in comparison with EMB samples in patients with clinically suspected MCI or iDCM.

\section{Methods}

\section{Population}

The study population consisted of 70 patients with clinically suspected MCI and iDCM, and 10 patients as a control group. Inclusion criteria were an episode of flu-like illness (respiratory tract infection, fever, dyspnea) within the last 12 months and at least 1 of the following features not related to myocardial ischemia: impaired global or regional left ventricle systolic function, increased serum concentration of myocardial necrosis markers, or nonsustained or sustained ventricular tachycardia or ventricular fibrillation of an unknown origin. Before EMB, all patients underwent physical examination and the following tests were performed: laboratory studies (C-reactive protein, complete blood count, Nterminal-pro-brain natriuretic peptide [NT-pro-BNP], and troponin I [TnI]), 12-lead electrocardiogram, echocardiography for the measurement of left ventricular end-diastolic diameter (LVEDD), and ejection fraction (LVEF) with planimetric Simpson's method and coronary angiography to exclude relevant coronary artery disease (diameter stenosis $>50 \%$ ). Eventually, patients with stable coronary artery disease created the control group, bearing in mind that they did not represent clinically healthy subjects, but rather those with a low probability of myocardial infection.

\section{Endomyocardial Biopsy and Histopathology}

The EMB was performed using a 7-Fr catheter bioptome (Cordis; Johnson \& Johnson, New Brunswick, NJ, USA) only in patients with the suspicion of myocardial infection. Two paraffinembedded specimens collected from the left ventricle were stained with hematoxylin and eosin and with Masson's trichrome. The categories of acute and borderline MCI according to the Dallas criteria were assessed jointly [13]. Localization and identification of mononuclear cell infiltrates were performed with antibodies against leukocyte common antigen, CD3, CD4, CD8 for T cells, and CD68 for macrophages (DAKO, Germany). Based on immunohistological criteria, inflammation was considered when focal or diffuse mononuclear infiltrates $\left(>14\right.$ leukocytes $/ \mathrm{mm}^{2}\left[\mathrm{CD}^{+} \mathrm{T}\right.$ lymphocytes and/or $\mathrm{CD}^{+} 8^{+}$macrophages]) were detected in the myocardial cells [13]. Two or 3 EMB specimens were quick-frozen in liquid nitrogen for molecular pathological exam including the real-time PCR method.

\section{Molecular Detection of the Viral Nucleic Acid}

Viral RNA and DNA were isolated from 2 separate EMB samples frozen in liquid nitrogen and the serum obtained from the left ventricle blood and peripheral blood samples collected at the time of biopsy. The viral nucleic acids were isolated from $20-50 \mu \mathrm{g}$ of the cardiac tissue with the NucleoSpin Tissue Kit (Macherey-Nagel) for DNA and with NucleoSpin RNA II kit (Macherey-Nagel) for RNA. The High Pure Viral Nucleic Acids Kit (Roche Diagnostics) was used for viral DNA and RNA isolation from $200 \mu \mathrm{L}$ of serum. Isolated DNA was suspended in $50 \mu \mathrm{L}$ of elution buffer, while the total amount of isolated RNA, eluted to a final volume of $27 \mu \mathrm{L}$, was transcribed immediately to $\mathrm{cDNA}$ by means of random hexamers and MMLV reverse transcriptase (Invitrogen). Isolation of DNA and RNA was performed according to the instructions supplied by the kits' manufacturers. Isolated DNA was used as a template for detection of 5 viruses, cytomegalovirus (CMV, HHV5), Epstein-Barr virus (EBV, HHV-4), HHV-6, HAdV, and PB19V, while cDNA was used for detection of HEV. 
Table 1. Characteristics of the study population

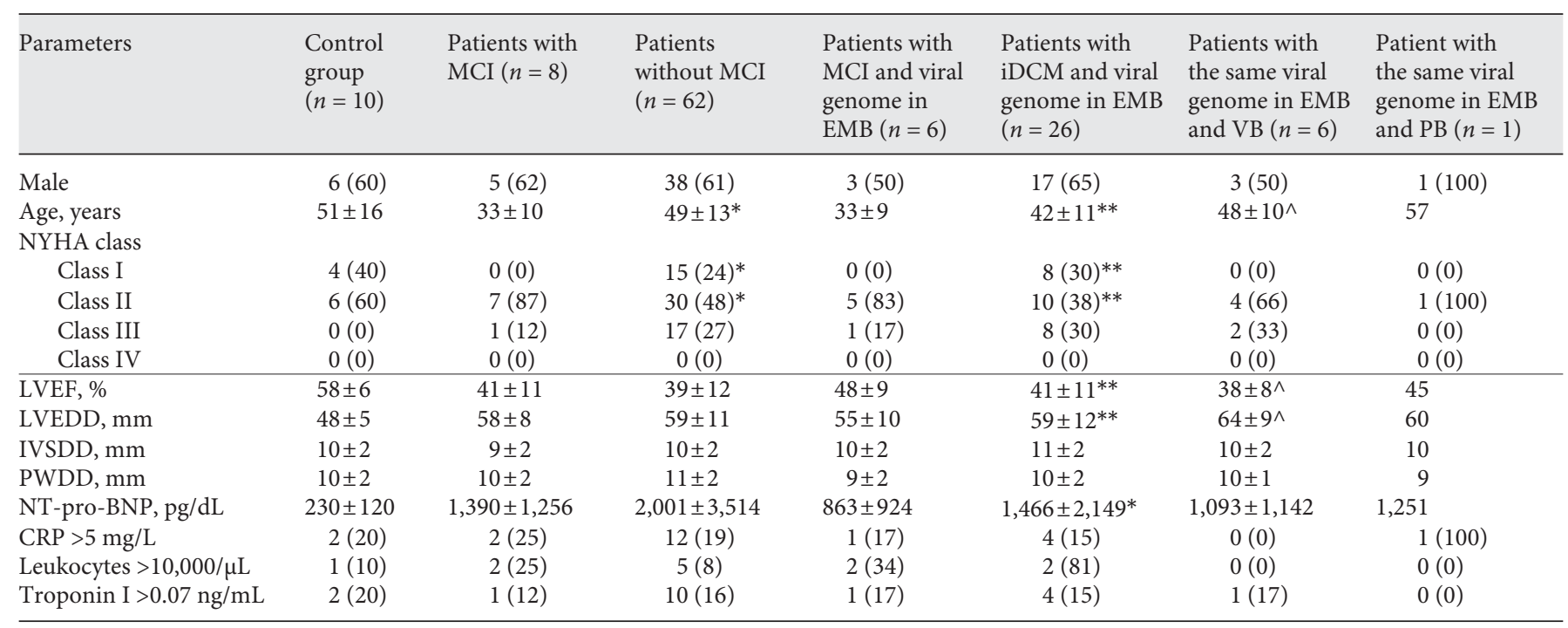

Data are presented as means $\pm \mathrm{SD}$, medians (with lower and upper quartiles), or $n(\%)$. ACE-I, angiotensin-converting enzyme inhibitor; ARB, angiotensin receptor blocker; LVEDD, left ventricle end diastolic diameter; LVEF, left ventricle ejection fraction; NT-pro-BNP, N-terminal pro-B-type natriuretic peptide; NYHA, New York Heart Association; CRP, C-reactive protein. ${ }^{*} p>0.05$ between groups with MCI and without MCI, ${ }^{* *} p>0.05$ between groups with viral genome in $\mathrm{EMB}$ and $\mathrm{MCI}$ and with viral genome in $\mathrm{EMB}$ and $\mathrm{iDCM}, \wedge p>0.05$ between groups with viral genome in $\mathrm{EMB}$ and $\mathrm{VB}$ and viral genome in EMB and MCI and with viral genome in VB and iDCM.

All examined viruses were detected with real-time PCR quantitative technique (qPCR). Commercially available kits were used for the detection of CMV (LightCycler CMV Quant Kit, Roche Diagnostics), EBV (LightCycler EBV Quant Kit, Roche Diagnostics), and PB19V (Parvovirus B19 Quantification Kit, Roche Diagnostics), and qPCR was performed according to the manufacturer's instructions. HHV-6, HAdV, and HEV were detected with qPCR methods utilizing TaqMan probes, developed and validated by the Chair and Department of Medical Microbiology at the Medical University of Warsaw [14-16]. For in-house methods, a series of calibrators prepared from quantified plasmids containing specific amplicon sequences were used (Rekom Biotech, Spain). To avoid false-positive results, a nontemplate control (NTC, Roche Diagnostics) was processed through all the steps of DNA/RNA isolation and viral nucleic acid amplification in the same manner as tested samples. Declared lower limits of quantification for qPCR methods were as follows: for CMV-235 copies of viral DNA per milliliter, for EBV-229 copies/mL, and for HHV-6-320 copies/mL. For the remaining methods, limits of quantitation have not been calculated. For the estimation of viral nucleic acid isolation efficacy from myocardial biopsies, all reactions were performed as duplex qPCR with primers and probes specific for human glucose6-phosphate dehydrogenase gene (G6PD) with further quantitation of G6PD copies and standardization of viral nucleic acids load by its recalculation to a number of viral nucleic acid copies per $10^{6}$ copies of G6PD gene (number of VNA copies per $10^{6}$ cells). The viral nucleic acid load in serum samples was expressed as copies/ $\mathrm{mL}$. All qPCR reactions were performed with a LightCycler 2.0 apparatus (Roche Diagnostics).

\section{Statistical Analyses}

Continuous variables were expressed as means \pm SD or as their logarithmic values, continuous variables with a skewed distribution as a median with lower and upper quartiles, and categorical variables as a percentage. Intergroup differences were analyzed with a Student $t$ test, whereas ANOVA was used for multiple group comparisons. Frequencies were compared using the $\chi^{2}$ test. All tests were 2 -sided with a significance level of $p \leq 0.05$. A commercial statistical package (SPSS v.13.0; IBM, Armonk, NY, USA) was used for all statistical analyses.

\section{Results}

\section{Patient Population}

Characteristics of the study population are presented in Table 1. The MCI was identified by histopathologic criteria only in $8(11 \%)$ patients. In patients without myocardial inflammation $(n=62,89 \%)$, the iDMC phenotype was observed in $44(63 \%)$ patients. Patients with MCI in comparison to patients without MCI were younger (33 \pm 10 vs. $49 \pm 13$ years) and had nonsignificantly better echocardiographic parameters regarding LVEF (41 \pm 11 vs. 39 $\pm 12 \%)$ and LVEDD $(58 \pm 8$ vs. $59 \pm 11 \mathrm{~mm})$. Patients were clinically stable but more symptomatic in the group with MCI (NYHA class II and III) than in the group with iDCM (NYHA classes I, II, and III) (Table 1). Clinical 
Table 2. Histopathological assessment and viral genome detection in endomyocardial biopsy samples

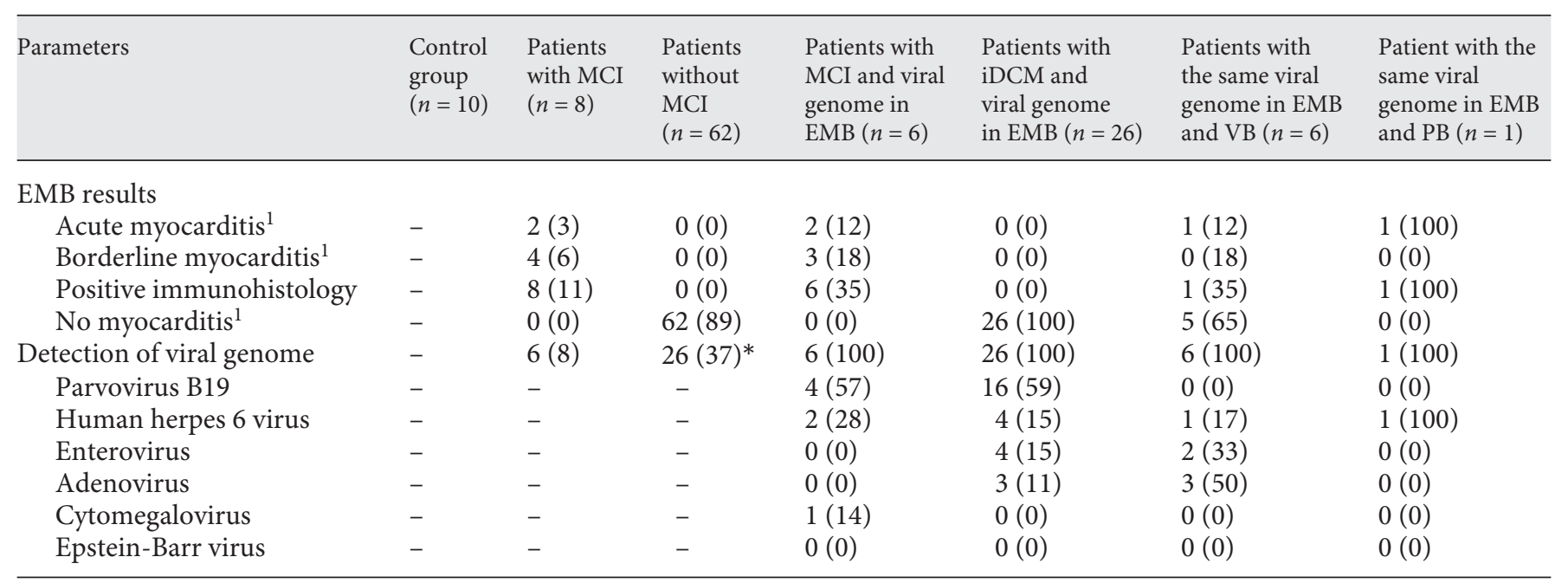

Values are given as $n(\%) .{ }^{*} p>0.05$ between groups with MCI and without MCI. ${ }^{1}$ Histopathology according to Dallas criteria.

symptoms, higher NT-pro-BNP level, larger LVEDD, and lower LVEF were seen more frequently in patients with iDCM and viral nucleic acids in EMB than in patients with MCI and viral nucleic acids in EMB (Table 1). Among patients with PB19V viral nucleic acids in EMB, those with iDCM were characterized by the highest NYHA class, NT-pro-BNP level, and lowest LVEF. Patients with the same type of viral nucleic acids in EMB and ventricular serum presented with statistically significant dilatation of the left ventricle and lower LVEF in comparison to patients with viral nucleic acids present only in EMB samples (Table 1).

The duration of history (antecedent flu-like illness to $\mathrm{EMB})$ was shorter in the group with $\mathrm{MCI}(3 \pm 3$ months) than in the group with iDCM (12 \pm 6 months).

\section{Histopathology and Immunohistochemistry}

Histopatological assessment, according to the Dallas criteria, revealed MCI in 6 (9\%) patients, including $2(3 \%)$ patients with acute MCI and 4 (6\%) patients with borderline MCI. Immunohistochemical staining of T-lymphocyte and macrophage infiltrates allowed to distinguish virus-positive and -negative patients only in $8(11 \%)$ cases (Table 2). In 1 of the $6(17 \%)$ patients with positive Dallas criteria, immunohistochemical staining and viral nucleic acids in EMB presented the same viral nucleic acids in ventricular serum and in EMB.

\section{Performance of qPCR Analysis in EMB Specimens}

Real-time PCR amplified viral nucleic acids in 32 of 70 EMBs $(46 \%)$ collected from patients with the final diagnosis of MCI ( $n=6$ of $8 ; 75 \%)$ and iDCM ( $n=26$ of 44 ; $59 \%$ ) (Table 1). Statistical differences were observed in the frequency $(p=0.01)$ of viral nucleic acid presence in EMB samples collected from patients with MCI or iDCM phenotype (Table 1; Fig. 1). Of these EMBs positive for viral nucleic acids, $3(50 \%)$ and $16(61 \%)$ patients were positive for BP19V, and $2(33 \%)$ and $4(15 \%)$ for HHV-6 in $\mathrm{MCI}$ and iDCM groups positive for viral nucleic acids, respectively. The HAdV genome was detected in $2(8 \%)$ patients and the HEV genome in $3(12 \%)$ patients only in the iDCM group positive for viral nucleic acids. In $2(3 \%)$ samples, more than 1 genome was found: PB19V and CMV in the MCI group and HEV and HAdV in the iDCM group. The EBV genome was not detected. In EMB samples, the average viral load was $3.93 \pm 0.57$ versus $3.23 \pm$ $0.83 \log _{10}$ copies $/ 10^{6}$ cells for PB19V, and $4.22 \pm 3.14$ versus $2.62 \pm 0.73 \log _{10}$ copies $/ 10^{6}$ cells for HHV- 6 in the MCI and iDCM groups, respectively. Furthermore, the average viral load was $2.99 \pm 0.52 \log _{10}$ copies $/ 10^{6}$ cells for HEV and $2.34 \pm 0.29 \log _{10}$ copies $/ 10^{6}$ cells for HAdV in patients with iDCM and $3.28 \log _{10}$ copies $/ 10^{6}$ cells for CMV in patients with MCI (Fig. 1). In all patients with iDCM and the HAdV genome in EMB, a low load of HAdV DNA was detected in ventricular but not in peripheral serum. In 2 patients out of 4 with iDCM and the HEV genome in the EMBs, ventricular serum was also 

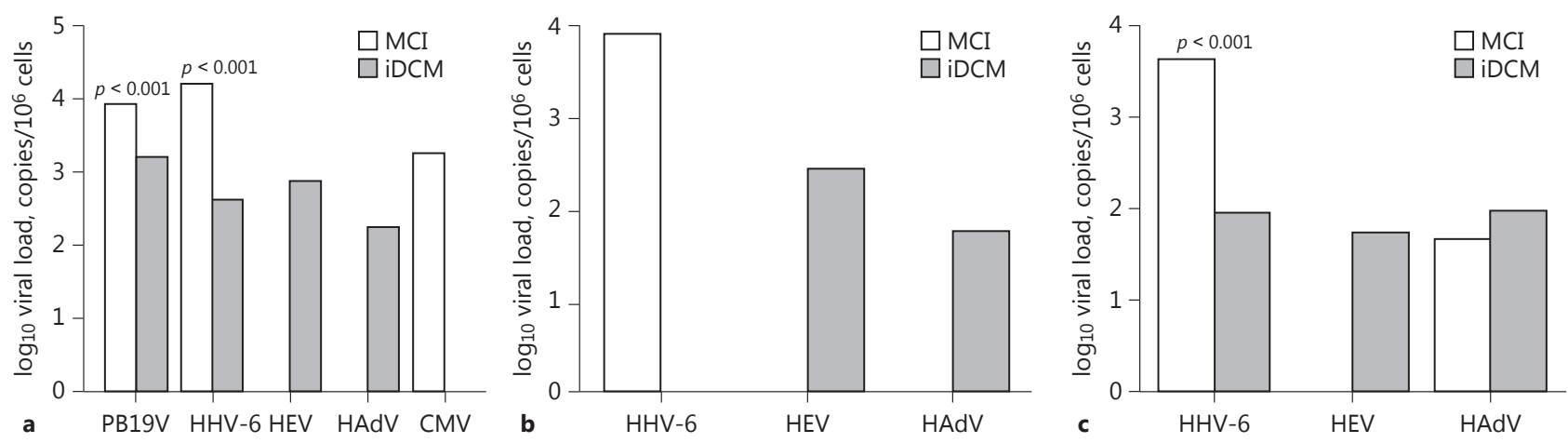

Fig. 1. Viral load in EMB (a), VS (b), and PS (c). EMB, endomyocardial biopsy samples; VS, ventricular serum samples; PS, peripheral serum samples; MCI, myocarditis; iDCM, inflammatory cardiomyopathy; HAdV, adenovirus; $\mathrm{HEV}$, enterovirus, HHV-6, human herpes virus type 6; PB19, parvovirus B19; CMV, cytomegalovirus.

positive for the HEV genome. Among patients EMB positive for HHV-6, HHV-6 was detected both in ventricular and peripheral serum in only 1 patient from the MCI group with a very high load of HHV-6 genome in EMB.

\section{Performance of qPCR Analysis in Ventricular Serum Samples}

The viral nucleic acids were found in ventricular serum samples of $10(14 \%)$ patients. HAdV $(n=5 ; 55 \%)$, $\operatorname{HEV}(n=3 ; 33 \%)$, and HHV-6 $(n=1 ; 11 \%)$ were detected in the 9 ventricular serum samples of the $32(28 \%)$ patients with EMB specimens positive for all types of viral nucleic acids. The same types of viral nucleic acids in ventricular serum samples and EMB specimens were observed in 6 out of $12(50 \%)$ patients positive for HAdV $(n=3 ; 100 \%$, all patients with iDCM), HEV $(n=2,50 \%$, all in the iDCM group), and HHV-6 ( $n=1,50 \%$, with $\mathrm{MCI}$ ) genome. In the 3 (2 with HAdV and 1 with HEV genome) ventricular serum samples of the 9 samples, other types of viral nucleic acids were found than in the EMB specimens. In these cases $\mathrm{PB} 19 \mathrm{~V}$ was observed in EMB and all patients were in the iDCM group. In the 1 ventricular serum sample out of 38 (3\%) collected from patients virus negative in EMB, HAdV was revealed (iDCM group). The genomes of $\mathrm{PB} 19 \mathrm{~V}$ and EBV were not detected in the ventricular or in the peripheral serum samples of any patient. The compliance of different types of viral nucleic acids in the ventricular serum samples with the cardiac tissue was observed in $60 \%$. Positive and negative results for viral nucleic acids in ventricular serum samples significantly correlated with the respective find- ings in EMBs $(p=0.001)$. The average HAdV load in the ventricular serum $\left(1.85 \pm 0.23 \log _{10}\right.$ of viral nucleic acids copies $/ \mathrm{mL}$ ) was low and comparable, both in the ventricular serum samples with the same and with different or lack of viral nucleic acids in EMB as well as in the patients with MCI or iDCM (Fig. 1). The average HEV load in the ventricular serum was $2.47 \pm 0.62 \log _{10}$ of viral nucleic acids copies/mL. In patients with the HEV genome detected in the ventricular serum and EMB samples simultaneously, the HEV viral nucleic acid loads in ventricular serum were even lower (70 and 300 copies $/ \mathrm{mL}$ ). The HHV -6 viral genome in ventricular serum $(8,000$ copies $/ \mathrm{mL})$ was observed only in 1 patient with a very high HHV-6 copy number in the EMB sample $\left(2,830,000\right.$ copies $/ 10^{6}$ cells $)$.

\section{Performance of qPCR Analysis in Peripheral Serum Samples}

The viral nucleic acids of the same viruses were detected in the peripheral as in the ventricular serum samples. Viral nucleic acids were found more often in the peripheral than in the ventricular serum $(n=14,20 \%$ vs. $n=10 ; 14 \%, p=0.02$, respectively).

HAdV $(n=4,28 \%)$, HEV $(n=2,14 \%)$, and HHV-6 $(n=2,14 \%)$ were detected in the 8 peripheral serum samples of the 32 (25\%) patients with EMB positive for viral nucleic acids. All above patients, except 2 with the HHV6 and HAdV viral genome in peripheral serum, were in the iDCM group. The coincidence of the same type of viral nucleic acids in the peripheral serum and EMB was low and observed only in 1 patient $(n=1,7 \%)$ with the HHV-6 viral genome and MCI. HAdV $(n=2,14 \%)$, HEV 
$(n=3,21 \%)$, and HHV $-6(n=1,7 \%)$ were found in the 6 peripheral serum samples of 38 (16\%) patients with EMB negative for viral nucleic acids. In this group all patients were in the iDCM group. Viral nucleic acids of the same virus as in the EMB sample was present more often in ventricular than in peripheral serum ( 60 vs. $7 \%, p=0.01$ ). The whole study population showed the accordance between the presence and lack of viral nucleic acids both in EMB and ventricular serum (62\%), and in EMB and peripheral serum (48\%). The viral nucleic acids were not detected in peripheral serum in the control group. The average viral load in the peripheral serum samples was low and comparable with the ventricular serum samples for HAdV $\left(2.24 \pm 0.29 \log _{10}\right.$ copies $\left./ \mathrm{mL}\right)$, HEV $(1.63 \pm 0.12$ $\log _{10}$ copies $\left./ \mathrm{mL}\right)$, and HHV-6 (2.46 $\pm 1.02 \log _{10}$ copies/ $\mathrm{mL}$ ) (Fig. 1). The significantly higher HHV-6 viral load (4300 copies $/ \mathrm{mL}$ ) in the peripheral serum sample in comparison with other peripheral serum samples positive for HHV -6 was found only in a patient with the HHV-6 genome in EMB and ventricular serum samples and with acute MCI.

\section{Discussion}

A clinically relevant diagnosis of MCI is achieved by the integration of clinical, histological, immunohistological, and molecular biological findings in EMB [17]. Since the fact of frequent viral nucleic acid prevalence in the myocardium is obvious, whether the persistent presence of viral nucleic acids is actively replicating in heart tissue or remains only an innocent bystander is now the key question. This information is important for prognosis and therapy. Therefore, new and more accurate markers that distinguish between active and chronic viral infection in the heart are required.

To our knowledge, this is the first known study in patients with viral nucleic acids in heart tissue to systematically assess the type and load of viral nucleic acids in the serum taken from peripheral blood and left ventricle blood samples when the viral nucleic acids can be directly released from heart tissue in groups with MCI and iDCM.

\section{Relevance of the Site Collection}

The detection of viral nucleic acids in serum collected from different sites was not taken into the consideration in patients with suspected MCI or iDCM; however, it was demonstrated that the sampling place is a critical factor for determining a difference in inflammatory cytokine values [18]. In an experimental study, Mella et al. [18] showed that the cytokines were dramatically elevated in ventricle blood compared with peripheral blood in infected mice. We suspected that this phenomenon can be possible in patients with MCI or/and iDCM not only regarding cytokines, but also viral nucleic acids. Possible mechanisms of release of viral nucleic acids from actively infected cells to blood is likely due to lytic replication, apoptosis of infected cells, or even extrachromosomal DNA release [19]. The significantly more frequent detection of the same viral nucleic acid type in the cardiac tissue and in ventricular serum than in peripheral serum in our study may suggest that the site of blood collection is important for more precise and reliable confirmation of the active viral infection in the heart.

\section{VNA in the Heart Tissue}

The spectrum of viruses that were detected in EMB in our study (PB19V, HEV, HAdV, and HHV-6) was comparable with the results of previously published studies [5, $20,21-24]$. The lower viral nucleic acid positivity rate in our study, particularly in the iDCM group, is not surprising considering the (1) very small samples collected during EMB compared with the tissue taken during open heart surgery, (2) analysis of EMB specimens obtained from iDCM patients with longer history and, consequently, possibly higher content of fibrotic tissue, (3) low amount of viral nucleic acids, especially in longstanding chronic MCI, and (4) lower number EMB samples dedicated to the molecular biological virus analysis. Many scientists have observed the coexistence of PB19V with HHV-6 in EMB (12-16\%), but our study revealed only PB19V/CMV and HEV/HAdV (3\%) coexistence [5, 21$23]$. The presence of the $\mathrm{PB} 19 \mathrm{~V}$ genome in $\mathrm{EMB}$, but not in ventricular or peripheral serum in both the MCI and iDCM groups, can result from involving antibody-dependent enhancement that probably leads to low-level replication with subsequent epigenetic silencing and conducts to nonproductive persistent presence of PB19V, or even its DNA, in endothelial cells of myocardium $[25,26]$. This seems to be sufficient in some cases to initiate clinically important noninflammatory cellular processes, such as apoptosis or autophagy, but in most cases stays as an innocent bystander, which will not trigger the release of progenitor virions to the bloodstream.

In the majority, values of PB19V viral load in our study indicated chronic viral infection both in the MCI and iDCM groups. These results are in agreement with those obtained from a study by Bock et al. [27]. Low-level replication of $\mathrm{PB} 19 \mathrm{~V}$ can partially explain the lack of PB19V 
viral nucleic acids in the bloodstream [27]. However, the lack of PB19V in blood in patients with a high viral load (range of 141,000 to 37,200 copies $/ 10^{6}$ cells) is more difficult to elucidate. On the other hand, in 1 case with a very high HHV-6 viral load in EMB, the HHV-6 genome was simultaneously observed in ventricular and peripheral serum. The higher HHV-6 viral load in ventricular serum than in peripheral serum can confirm our hypothesis that it is more probable to detect heart tissue infection based on examination of ventricular than peripheral serum. According to Lévêque et al. [28], a low viral load of HEV in $\mathrm{EMB}$ and low positive to negative RNA ratios seems to be a sensitive marker of HEV persistence in $\mathrm{iDCM}$ patients. The low HEV and HadV viral load in EMB in patients with iDCM in our study can also indicate virus persistent infection. However, we suspect that the presence of viral load in ventricular serum can show the active replication of the virus in iDCM patients. The worst clinical and echocardiographic parameters in the group with the same type of viral nucleic acids in EMB and ventricular serum can indirectly confirm our assumption. The mechanisms that lead to the increase in viral load in ventricular serum in patients with virus-persistent infection remain unclear.

\section{VNA in the Blood}

Detection of viral nucleic acids in peripheral leukocytes may indicate recent viral infection, viral reactivation, or persistent infection [29]. The studies performed in patients with viral disease other than MCI have demonstrated that leukocyte samples have the highest sensitivity for viral nucleic acid detection compared to plasma and serum [30]. Some have suggested that by using a highly sensitive sample, one can identify viral disease in patients with low viral loads, but the specificity of detecting low-level viral nucleic acids in leukocyte samples for predicting viral disease is limited, as may be associated with detection of persistent or latent virus [30]. Moreover, it is also possible that use of oversensitive assays may result in the unnecessary or excess treatment, or a longer course of antiviral therapy, as observed in CMV infections of transplant recipients [30]. Therefore, the use of serum has been advocated as being more indicative of active viral infection [30]. So far, active viral replication has been shown by high absolute viral load values or a rising trend in viral loads [31]. Classical morphological analysis (histology and immunohistochemistry) has great limits in indication of viral etiology of pathogenic process. The lack of correlation between conventional histological signs of MCI and the presence of viral nucleic acids in

Viral Nucleic Acids in the Serum Are Dependent on Blood Sampling Site cardiac tissue has been previously reported $[5,32]$. This is in agreement with our study, which also confirms that routine histological analysis is too insensitive to indicate the presence of viral nucleic acids in EMB samples. In our data, a low-to-average level viral load in EMB samples was demonstrated predominantly, which should indicate a chronic persistent presence of virus in cardiac tissue. Interestingly, in 5 patients with a low-level viral load (HAdV, HEV) in EMB, a low-level viral load in ventricular serum was also found, which suggests the active persistent presence of viral nucleic acids in the myocardium. At the same time, no viral nucleic acids in peripheral serum were observed. The lack of a viral genome in peripheral serum was surprising not only for us, but also for other scientists who did not observe viral nucleic acids in peripheral plasma [20].

It is worth emphasizing that the same viral nucleic acids in EMB and ventricular serum were observed mainly in patients with chronic viral heart infection. We should keep in mind that PB19V is detected in peripheral blood very rarely, i.e., when MCI is followed as a consequence of primary infection of PB19V [20,33]. It seems possible that the evaluation of the viral genome in ventricular serum and EMB can distinguish patients with a low viral genome load in cardiac tissue and active replication from patients with a low viral genome load and chronic persistent presence of virus. Thus, we may suspect that the same viral nucleic acids present in the ventricular serum and EMB may be simple and unique markers, which indicate active virus reservoirs in the cardiac tissue. Moreover, patients with the same viral nucleic acids in EMB and ventricular serum presented clinical symptoms more frequently and worse echocardiographic parameters than patients with viral nucleic acids detected only in EMB both in the MCI and iDCM groups. Therefore, the presence of the same viral nucleic acids in ventricular serum and EMB may be the important parameter for diagnosis, prognosis, and a therapeutic decision. The presence of the same viral nucleic acids (HHV-6) was observed in the ventricular and the peripheral serum in only 1 case, but was observed in patients with high-load viral nucleic acids in EMB and acute viral heart infection. Recently, Jeserich et al. [29] showed the presence of viral nucleic acids in peripheral plasma, but only in patients with acute viral infection and a high-level viral load in EMB.

Regarding PB19V, the results of our study indicate a local presence of the persistent form of $\mathrm{PB} 19 \mathrm{~V}$ in the cardiac tissue rather than active infection caused by the virus translocated from the bone marrow since viral DNA was found neither in ventricular nor peripheral serum. 
We cannot exclude the possibility of PB19V primary infection in childhood persisting in more than $70 \%$ of the adult population after infection [34-36]. The presence of HAdV and HEV in peripheral serum, but not in the cardiac tissue, remains difficult to interpret, as there is no data concerning the results of viral nucleic acid detection in case of HAdV or HEV in peripheral serum of patients with MCI or iDCM. However, such investigations are performed extensively in immunosuppressed patients receiving hematopoietic stem cell transplantations and asymptomatic HAdV infections with detectable DNAemia. HAdV and HEV are observed in 4-14\% of hematopoietic stem cell transplantation recipients and in up to $2.7 \%$ of patients not receiving immunosuppression [25, 37]. Although there are no clear risk factors in the group of patients with MCI or iDCM, some (difficult-to-assess) levels of immunosuppression related mainly to innate immunity can be taken into consideration [26].

\section{Limitations}

There are a few possible limitations of this study. First, we did not perform the analysis of qPCR in leukocytecontaining blood samples. Although this might have provided interesting information, it also required additional blood samples. Further, the increase in blood volume, which was high enough (samples taken from 2 sites, analysis of other biochemical parameters), could cause a disadvantage for patients. Moreover, based on the literature, it is known that the analysis of peripheral leukocytes cannot answer questions about the activity of viral infection in cardiac tissue. Second, the number of patients in the subgroups with HAdV, HEV, and HHV-6 should be more numerous. In the future, a larger study population and longer follow-up is needed to precisely evaluate the clinical meaning of our findings.

\section{Conclusions}

The detection of the same type of viral nucleic acids in the cardiac tissue and in ventricular serum significantly more frequently than in peripheral serum may suggest that the site of the blood collection is important for more precise and reliable confirmation of active viral replication in the heart. The detection of viral nucleic acids in peripheral serum seems to be irrelevant for identifying the viral infection in patients with a low virus load in cardiac tissue. It seems possible that the evaluation of the viral genome in ventricular serum and EMB can distinguish patients with low viral genome load in cardiac tissue and active replication from patients with a low viral genome load and chronic persistent presence of virus. Further evaluation of EMB and blood compartments should be conducted. However, these results need to be confirmed in a larger population of patients.

\section{Acknowledgment}

We would like to thank Professor Dr. Sabine Pankuweit for fruitful advice and suggestions. This work was supported by the National Science Center(Poland) grant No. 2014/13/B/NZ4/03832.

\section{Ethics Statement}

The local ethics committee of the Central Clinical Hospital of the Ministry of Interior in Warsaw approved the study (No. 56/2012).

\section{Disclosure Statement}

The authors report no conflicts of interest.

\section{References}

1 Yajima T, Knowlton KU: Viral myocarditis: from the perspective of the virus. Circulation 2009;119:2615-2624.

2 Kindermann I, Barth C, Mahfoud F, et al: Update on myocarditis. J Am Coll Cardiol 2012; 59:779-792.

3 Caforio ALP, Pankuweit S, Arbustini S, et al: Current state of knowledge on aetiology, diagnosis, management, and therapy of myocarditis: a position statement of the European Society of Cardiology Working Group on Myocardial and Pericardial Diseases. Eur Heart J 2013;34:2636-2648.
4 Schenk T, Enders M, Pollak S, Hahn R, Huzly D: High prevalence of human parvovirus B19 DNA in myocardial autopsy samples from subjects without myocarditis or dilative cardiomyopathy. J Clin Microbiol 2009;47:106-110.

5 Kühl U, Pauschinger $M$, Noutsias $M$, et al: High prevalence of viral genomes and multiple viral infections in the myocardium of adults with 'idiopathic' left ventricular dysfunction. Circulation 2005;111:887-893.

6 Kindermann I, Kindermann M, Kandolf R, Klingel K, Bultmann B, Muller T, Lindinger A, Böhm M: Predictors of outcome in patients with suspected myocarditis. Circulation 2008; 118:639-648.

7 Kühl U, Noutsias M, Seeberg B, Schultheiss HP: Immunohistological evidence for a chronic intramyocardial inflammatory process in dilated cardiomyopathy. Heart 1996; 75:295-300.

8 Razonable RR, Brown RA, Wilson J, Groettum C, Kremers W, Espy M, Smith TF, Paya CV: The clinical use of various blood compartments for cytomegalovirus (CMV) DNA quantitation in transplant recipients with CMV disease. Transplantation 2002;73:968-973. 
9 Evans PC, Soin A, Wreghitt TG, Alexander GJ: Qualitative and semiquantitative polymerase chain reaction testing for cytomegalovirus DNA in serum allows prediction of CMV related disease in liver transplant recipients. J Clin Pathol 1998;51:914-921.

10 Cunningham R, Harris A, Frankton A, Irving W: Detection of cytomegalovirus using PCR in serum from renal transplant recipients. J Clin Pathol 1995;48:575-577.

11 Eckart P, Brouard J, Vabret A, Freymuth F, Guillot M, Ryckelynck JP, Hurault de Ligny B: Detection of human cytomegalovirus in renal transplantation: comparison of four diagnostic methods: DNA in sera by polymerase chain reaction (PCR), DNA in leukocyte by PCR, pp65 leukocytic antigenemia, and viremia. Transplant Proc 1997;29:2387-2389.

12 Mahfoud F, Gärtner B, Kindermann M, et al: Virus serology in patients with suspected myocarditis: utility or futility? Eur Heart J 2011;32:897-903.

13 Richardson $\mathrm{P}$, McKenna W, Bristow M, Maisch B, Mautner B, O'Connell J, Olsen E, Thiene G, Goodwin J, Gyarfas I, Martin I, Nordet P: Report of the 1995 World Health Organization/International Society and Federation of Cardiology Task Force on the Definition and Classification of cardiomyopathies. Circulation 1996;93:841-842.

14 Leś K, Przybylski M, Dzieciątkowski T, et al: Zastosowanie metody real-time PCR do wykrywania HEV człowieka. Med Dosw Mikrobiol 2010;62:245-253.

15 Dzieciątkowski T, Przybylski M, Gieryńska $\mathrm{M}$, et al: Wykorzystanie metody real-time PCR do wykrywania DNA ludzkiego herpeswirusa typu 6. Med Dosw Mikrobiol 2008; 60:259-265.

16 Rola A, Przybylski M, Dzieciątkowski D, et al: Zastosowanie metody real-time PCR z użyciem sond Taqman do wykrywania zakażeń adenowirusami człowieka. Med Dosw Mikrobiol 2007;59:371-377.

17 Kandolf R: Diagnosis of myocarditis. Dtsch Med Wochenschr 2011;136:829-835.
18 Mella JR, Chiswick EL, King E, Remick DG: Location, location, location: cytokine concentrations are dependent on blood sampling site. Shock 2014;42:337-342.

19 Jensen KJ, Garmaroudi FS, Zhang J, Lin J, Boroomand S, Zhang $\mathrm{M}$, Luo Z, Yang $\mathrm{D}$, Luo $\mathrm{H}$, McManus BM, Janes KA: An ERK-p38 subnetwork coordinates host cell apoptosis and necrosis during coxsackievirus B3 infection. Cell Host Microbe 2013;13:67-76.

20 Kuethe F, Lindner J, Matschke K, et al: Prevalence of parvovirus B19 and human bocavirus DNA in the heart of patients with no evidence of dilated cardiomyopathy or myocarditis. Clin Infect Dis 2009;49:1660-1666.

21 Kühl U, Pauschinger M, Seeberg B, et al: Viral persistence in the myocardium is associated with progressive cardiac dysfunction. Circulation 2005; 112:1965-1970.

22 Dennert R, Crijns HJ, Heymans S: Acute viral myocarditis. Eur Heart J 2008;29:2073-2082.

23 Mahrholdt H, Wagner A, Deluigi CC, et al: Presentation, patterns of myocardial damage, and clinical course of viral myocarditis. Circulation 2006;114:1581-1590.

24 Donoso Mantke O, Nitsche A, Meyer R, Klingel K, Niedrig M: Analysing myocardial tissue from explanted hearts of heart transplant recipients and multi-organ donors for the presence of parvovirus B19 DNA. J Clin Virol 2004;31:32-39.

25 Yaghobi R, Langari MJ, Ramzi M, Geramizadeh B, Zakerinia M, Khojasteh HN, Dehghani M: Molecular impact and inducible factors associated with adenovirus infection in hematopoietic stem [corrected] cell transplant patients. Transplant Proc 2011;43:644-646.

26 Kühl U, Schultheiss HP: Viral myocarditis: diagnosis, aetiology and management. Drugs 2009;69:1287-1302.

27 Bock CT, Klingel K, Kandolf R: Human parvovirus B19-associated myocarditis. N Engl J Med 2010;362:1248-1249.

28 Lévêque N, Renois F, Talmud D, Nguyen Y, Lesaffre F, Boulagnon C, Bruneval P, Fornes P, Andréoletti L: Quantitative genomic and antigenomic enterovirus RNA detection in explanted heart tissue samples from patients with end-stage idiopathic dilated cardiomyopathy. J Clin Microbiol 2012;50:3378-3380.
29 Jeserich M, Brunner E, Kandolf R, Olschewski M, Kimmel S, Friedrich MG, Föll D, Bode C, Geibel A: Diagnosis of viral myocarditis by cardiac magnetic resonance and viral genome detection in peripheral blood. Int J Cardiovasc Imaging 2013;29:121-129.

30 Lisboa LF, Asberg A, Kumar D, Pang X, Hartmann A, Preiksaitis JK, Pescovitz MD, Rollag $\mathrm{H}$, Jardine AG, Humar A: The clinical utility of whole blood versus plasma cytomegalovirus viral load assays for monitoring therapeutic response. Transplantation 2011;91:231236.

31 Emery VC, Sabin CA, Cope AV, Gor D, Hassan-Walker AF, Griffiths PD: Application of viral-load kinetics to identify patients who develop cytomegalovirus disease after transplantation. Lancet 2000;355:2032-2036.

32 Basso C, Calabrese F, Angelini A, Carturan E, Thiene G: Classification and histological, immunohistochemical, and molecular diagnosis of inflammatory myocardial disease. Heart Fail Rev 2013;18:673-681.

33 Adda J, Machado S, Eberst E, Roubille C, Macia JC, Roubille F: Parvovirus B19 infection and acute myocarditis. Inter Med 2010;49:79.

34 Bültmann BD, Klingel K, Sotlar K, Bock CT, Baba HA, Sauter M, Kandolf R: Fatal parvovirus B19-associated myocarditis clinically mimicking ischemic heart disease: an endothelial cell-mediated disease. Hum Pathol 2003;34:92-95.

35 Kühl U, Pauschinger M, Bock T, et al: Parvovirus $\mathrm{B} 19$ infection mimicking acute myocardial infarction. Circulation 2003;108:945950.

36 Schultheiss HP, Kühl U, Cooper LT: The management of myocarditis. Eur Heart I 2011;32:2616-2625.

37 Suparno C, Milligan DW, Moss PA, Mautner $\mathrm{V}$ : Adenovirus infections in stem cell transplant recipients: recent developments in understanding of pathogenesis, diagnosis and management. Leuk Lymphoma 2004;45:873885 .
Viral Nucleic Acids in the Serum Are

Dependent on Blood Sampling Site
Intervirology 2016;59:143-151

DOI: $10.1159 / 000452834$ 